\title{
Yüksek Frekanslarda İnsan Derisinin Kablosuz Vücut Alan Ağlarına Etkisi
}

\author{
Human Skin Effects in Wireless Body Area Networks at High Frequencies
}

\author{
Mustafa Alper AKKAŞ ${ }^{1, a}$ Tunçer BAYKAŞ ${ }^{* 2, b}$ \\ ${ }^{1}$ Abant İzzet Baysal Üniversitesi, Mühendislik Mimarlık Fakültesi, Bilgisayar Mühendisliği Bölümü, 14030, Bolu \\ ${ }^{2}$ İstanbul Medipol Üniversitesi, Mühendislik Fakültesi, Bilgisayar Mühendisliği Bölümü, 34810, İstanbul
}

\begin{abstract}
• Geliş tarihi / Received: 22.02.2019 • Düzeltilerek geliş tarihi / Received in revised form: 06.09.2019 • Kabul tarihi / Accepted: 16.09 .2019
\end{abstract}
\begin{abstract}
$\ddot{\mathbf{O z}}$
Mikro elektronik ve entegre devreleri, çip üzerinde sistem tasarımı, kablosuz haberleşme ve düşük güçlü akıllı sensörlerdeki son gelişmeler Kablosuz Vücut Alan Ağlarının (KVAA) gerçekleşmesini sağlamıştır. KVAA insan vücudu işlevlerini ve çevreleyen ortamı inceleyen düşük güçlü, minyatürize edilmiş, invaziv veya invaziv olmayan, hafif telsiz duyarga ağlarının toplamıdır. Bu çeşit ağlarda çeşitli duyarga ağları giysilere, vücuda ve hatta derinin altına yerleştirilmektedir. Ağın kablosuz oluşu ve duyarga ağlarının çeşitliliği birçok pratik ve yenilikçi uygulamalar sayesinde yaşam kalitesini ve sağlığını artırmaktadır. KVAA yardımı ile hasta çok daha geniş bir hareket özgürlüğüne kavuşacak ve hastanın hastane ortamında kalmasına gerek kalmayacaktır. Bu makalede Elektromanyetik (EM) dalgaların deri içerisinde yayılımına göre modellenmesi incelenmiştir. Yayılma özellikleri teorik olarak incelenmiştir. Makalede EM dalgalarının deri ortamında GHz bant aralığında teorik olarak yol kaybı incelenerek, Bit Hata Oranları (BHO) ve yol kaybı hesaplanmıştır. Teorik analizler ve benzetim sonuçları, deri ortamında $30 \mathrm{GHz}-300 \mathrm{GHz}$ bant aralığında kablosuz haberleşmenin sağlanabileceğini göstermekte ve bu alandaki birkaç önemli hususu vurgulamaktadır.
\end{abstract}

Anahtar kelimeler: Deri Altı Duyarga Düğümü, Elektromanyetik Modelleme, Hasta Takip, Kablosuz Vücut Alan Ağları, Sağlık Hizmeti.

\begin{abstract}
Recent developments in intelligent low-power sensors, microelectronics, system-on-chip design, integrated circuits and wireless communication have allowed the realization of a Wireless Body Area Network (WBAN). A WBAN is a combination of miniaturized, low-power, invasive/non-invasive lightweight wireless sensor nodes that monitor the human body functions and the surrounding environment. In these networks various sensor nodes are attached on clothing or on the body or even implanted under the skin. The wireless network and the wide variety of sensors offer numerous new, practical and innovative applications to improve health care and the quality of life. With the help of WBAN the patient experiences a greater physical mobility and is no longer compelled to stay in the hospital. In this paper the skin communication channel is modelled considering the propagation of Electromagnetic (EM) waves in skin. The propagation characteristics are investigated using a theoretical approach. More specifically, the paper sets the theoretical background for examining the path loss of EM waves propagating in skin in the GHz range and determines the incurred path loss and Bit Error Rate (BER). The theoretical analysis and the simulation results prove the feasibility of wireless communication in the $30 \mathrm{GHz}-300 \mathrm{GHz}$ band in skin and highlight several important aspects in this field.
\end{abstract}

Keywords: Subcutaneous Sensor, Electromagnetic Modelling, Patient Tracking, Wireless Body Area Network, Healthcare.

\footnotetext{
${ }^{a}$ Mustafa Alper Akkaş, alperakkas@ibu.edu.tr; orcid.org/ 0000-0003-0185-0464

*borcid.org/ 0000-0001-9535-2102
} 


\section{Giriş}

Teknoloji gün geçtikçe sağlık sektöründe daha çok yer almaktadır. Derinin altına yerleştirilmiş bir duyarga düğümünün, bağlı olduğu mikroişlemci sayesinde gerekli bilgileri hastaya ya da doktoruna gönderdiği düşünülürse, vücuttaki farklılıklar önceden tespit edilecek ve erken müdahalenin önü açılmış olacaktır. Deri altına yerleştirilmiş ara yüz, aktif telsiz duyarga ağ1 gibi davranıp gerekirse vücudun içinde dolaşan diğer telsiz duyarga ağlarıly bağlantıya geçip toplanan bilgiyi iletebilecektir. İkinci bir alternatif ise anlık kan ve hormon seviyelerini analiz ederek normal değerlerin dışına çıkıldığında hastayı ya da ilgili birimi uyaracaktır (Pieboron ve Akyildiz, 2010; Atakan, B. vd, 2012)
Haberleşme teknolojisinde en çok kullanılan haberleşme metotlarından biri, klasik haberleşme metodu olan elektromanyetik haberleşmedir. Elektromanyetik haberleşmede EM dalgalar, haberleşme ortamında ilerledikçe soğrulur. EM dalgaların soğrulması taşıyıcının kullandığı frekansa göre değişir. Bu çalışmada $30 \mathrm{GHz}$ 'den 300 GHz'e kadar olan EM dalgaların deri ortamında nasıl soğruldukları matematiksel olarak modellenecektir. $30 \mathrm{GHz}-300 \mathrm{GHz}$ aralığı, küçük boyutta anten tasarlamak için oldukça ideal bir aralıktır. $100 \mathrm{GHz}-300 \mathrm{GHz}(0.1 \mathrm{THz}-0.3$ $\mathrm{THz}$ ), nano boyutta anten tasarlamaya uygun bir frekans aralı̆̆ıdır (Akyildiz, Ian F., v.d., 2012). Biyomedikal teknolojisinde sadece elektromanyetik haberleşme değil, farklı haberleşme metotlarının kullanılması da hedeflenmektedir. Bunlardan bir tanesi moleküler haberleşmedir.

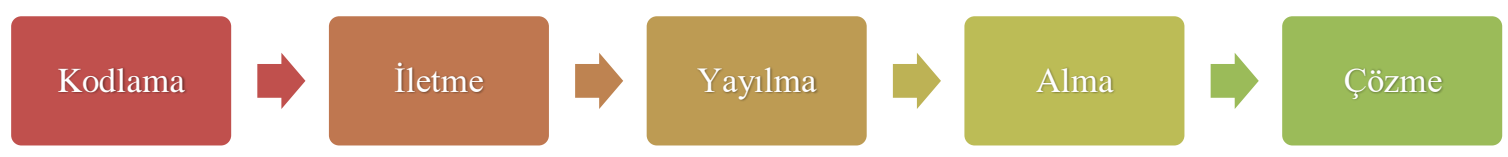

a) Klasik elektromanyetik haberleşme adımları
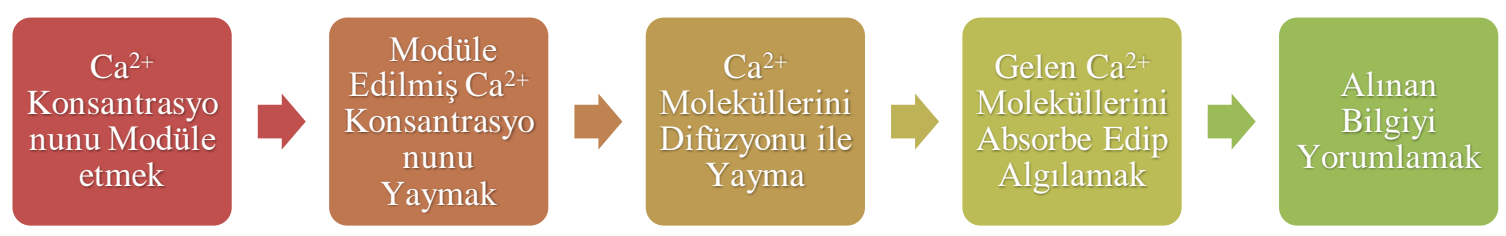

b) Moleküler Haberleşme-1: Çok kısa mesafe $\mathrm{Ca}^{2+}$ haberleşmesi
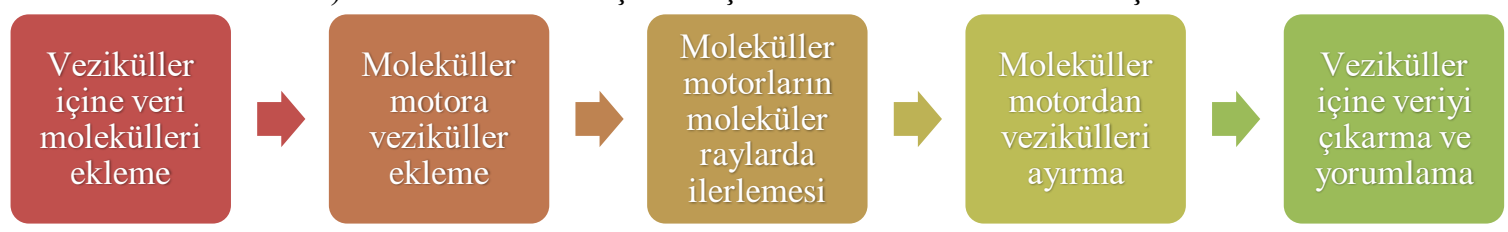

c) Moleküler Haberleşme-2: Çok kısa mesafe moleküler motor haberleşmesi
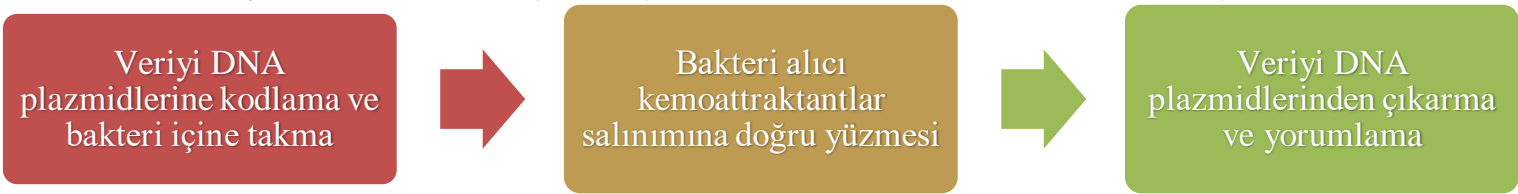

d) Moleküler Haberleşme-3: Orta menzilli - bakteriyel kemotaksi ve konjugasyon
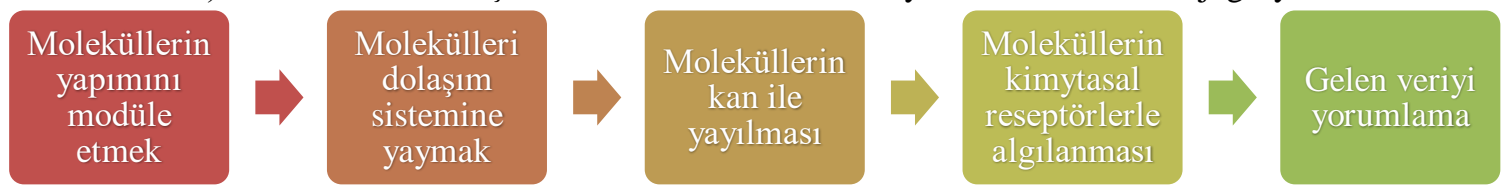

e) Moleküler Haberleşme-4: Uzun mesafe hormonal haberleşme

Şekil 1. Biyomedikalde kullanılan haberleşme metotları

Moleküler haberleşme, günümüzde incelenen önemli bir konudur. Fakat çözülmesi gereken birçok problemi vardır. Örneğin, moleküler sinyaller elektromanyetik sinyaller gibi yönünü tayin edemez. Moleküler haberleşmede bir nevi sinyal iletişimi rastgele olur. Bu yüzden yeni veri 
iletme ve ortak kanalı kullanma gibi yeni metotlar geliştirilmelidir.

Moleküler haberleşmedeki çözüm önerileri bakterilerde olduğu gibi, "kanal modelleme", "analiz etme" ve "tekrar kullanma" dir (Nakano, T., v.d. 2012.; Dixon, R. A. ve Christopher J. L., 1990). Şekil 1, klasik haberleşme adımlarının moleküler haberleşme metotlarıyla mukayesesini göstermektedir. Moleküler haberleşme adımları, temel olarak klasik haberleşme (Şekil 1a) adımıyla benzerlik gösterir. Moleküler haberleşmede haberleşme menziline göre haberleşme metodu farkl111k gösterebilir. Kısa mesafelerde taşıyıcı olarak $\mathrm{Ca} 2+$ veya moleküllerle sağlanırken (Şekil 1b, Şekil 1c) orta menzilli haberleşmede bakteriler taşıyıcı olarak kullanılır (Şekil 1d). Vücut içi uzun menzilli haberleşmelerde ise hormonların taşıyıcı olarak kullanılması hedeflenmektedir (Şekil 1e) (Giné, L. ve Akyildiz I., 2009) .

Moleküler haberleşmenin elde etmek istediği verileri, insan vücudu kendi sistemleri sayesinde algılayabilmektedir. Moleküler haberleşmenin amac1; vücudun kendi sistemine adapte olarak sıra dışı durumlarda sağlık birimini bilgilendirmektir. İnsan vücudunda ise haberci moleküller iki ana gruba ayrilmaktadır. Bunlar birincil ve ikincil habercilerdir. Büyüme gibi hormonal olaylarla ilgilenen habercilere birincil haberciler denir. Birincil haberciler çok fazla çeşitlilik gösterirler ve hücrelerin birbirleri ile haberleşmelerini sağlarlar. İkincil haberciler ise birincil habercilerden farklı olarak hücre içi haberleșme ile ilgilenirler. İkincil haberciler molekülleri birinci haberci moleküllerinden aldıkları haberleri hücre içine yayarlar. Bu haberleşme adımları çok sayıda molekülün katıldığı karmaşık olaylar ve organizasyonlar içerir. Haberci moleküllerin taşınması farklı şekillerde olabilir. Haberin taşınacağı hücreler konumu birbirlerine bitişik, yakın ya da uzak olabilir. $\mathrm{Bu}$ durum sinir hücrelerinde farkl1lık gösterir. Sinir hücrelerinin gövdeleri birbirlerinden çok uzak olabilir ancak tıpk1 bitişik hücrelerde olduğu gibi gövdeden çıkan uzantılar ile hücreler arasında temas sağlanmaktadır (Atakan, B. ve Akan. O.B., 2007; Çoşkun, A., 2011)

Biyomedikal haberleşmede moleküler ya da elektromanyetik olarak vücut içinden toplanan veriler bir şekilde kullanıcılara ulaştırılmalıdır. $\mathrm{Bu}$ mimarinin ara yüzü Şekil 2'de gösterilmiştir. Bu araştırmada ise, insanın deri altına yerleştirilen biyolojik-sanal ara yüzün, deri tarafindan elektromanyetik dalga kullanıldığında frekanslara göre nasıl emildiğini incelenmektedir.

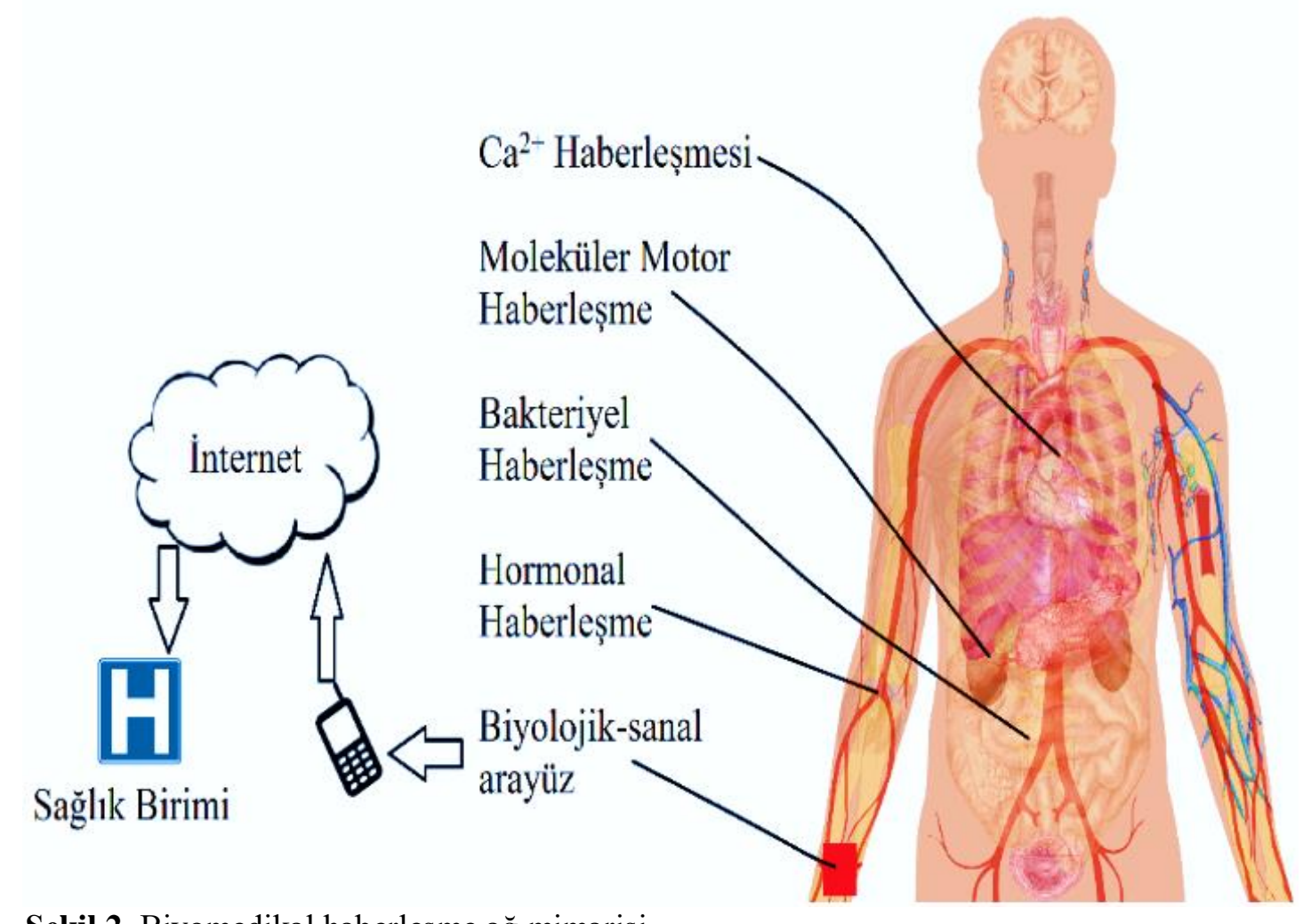

Şekil 2. Biyomedikal haberleşme ağ mimarisi 


\section{Materyal ve Metot}

EM dalgalarının modellenmesinde başlangıç formülü Friis Denklemi'dir (Roh, W. 2014). Friis Denklemi Eş. 1'de gösterilmiştir. Eş. 1'de boşluk ortamında $P_{t}$ verici antenin taşıma gücünü, $d$ uzaklık, $G_{r}$ ve $G_{t}$ alıcı ve verici antenlerin kazancını göstermektedir.

$$
\begin{aligned}
& \frac{P_{r}}{P_{t}}=G_{t} G_{r}\left(\frac{\lambda}{4 \pi R}\right)^{2} \\
& P_{r}=P_{t}+G_{t}+G_{r}+20 \log _{10}\left(\frac{\lambda}{4 \pi R}\right)
\end{aligned}
$$

$\mathrm{Bu}$ sistem, ayrıca Eş. 2'de gösterilmiş olan boş alan yol kaybindan da etkilenmektedir. $d$ uzaklığının birimi km ve frekans değeri GHz'dir.

$$
\begin{aligned}
& \text { Boş Alan Yol Kaybl }(d B)=10 \log _{10}\left(\left(\frac{4 \pi d f}{c}\right)^{2}\right) \\
& =20 \log _{10}(d)+20 \log _{10}(f)+20 \log _{10}\left(\frac{4 \pi}{c}\right) \\
& =20 \log _{10}(d)+20 \log _{10}(f)-147.55
\end{aligned}
$$

Fakat farklı ortam haberleşmesinde ortamdan kaynaklanan kayıp ve gürültü kaybı olan sistem kayb1 da eklenmelidir (Ghodgaonkar, D. K., v.d. 1989). Bu çalışmada deri ortamındaki kayıplar boş alan kaybına dahil edilmiştir. Bu kayıpların ve gürültü kaybının $\mathrm{dBm}$ şeklinde ifade edilmesi Eş. 3 'te gösterilmektedir.

$$
L_{N P}=10 \log _{10}(1000 * k * T * B)(d B m)
$$

Burada T'nin birimi Kelvin, $B$ 'nin ise birimi $\mathrm{Hz}$ cinsinden frekans bant genişliğidir. $k$ ise Boltzmann sabiti olan yaklaşık $1.3801 \times 10-23$ $j / K$ 'ya eşittir. $\mathrm{Bu}$ araştırmada sicaklık, ortam sıcaklığı olan 296 Kelvin alınmıştır. Deri ortamının zayıflama formülleri ise Eş. 4 ile başlar.

$$
\begin{gathered}
K_{D E R I}=K_{\beta}+K_{\alpha} \\
K_{\beta}=20 \log \left(\frac{\lambda_{0}}{\lambda}\right)=154-20 \log (f)+20 \log (\beta) \\
K_{\alpha}=8.69 \alpha d
\end{gathered}
$$

$K_{\beta}$, deri ortamında dalga boyunda ki zayıflama kaybıdır. $K_{\beta}$, deri ortamının dalga boyunu ifade eder ve açılımı $\beta=2 \pi / \lambda$ 'dır. $\beta$ faz kayma sabitidir. Bilindiği gibi $\lambda_{0}=c / f$ boş alan yol kaybıdır ve boş olan yol kaybının orantısı $K_{\beta}$ 'ye eşittir. $K_{\alpha}$ ise deri ortamından kaynaklanan zayıflama kaybıdır. $\alpha$, iletim kaybını simgeler.

Deri ortamın tüm kayıp ve kazançlarının toplanmış halde gösterimi Eş. 5'te gösterilmiştir.

$$
K_{\text {Deri }}=6.4+20 \log (d)+20 \log (\beta)+8.69 \alpha d
$$

Eş. 5'te ki, $\alpha$ zayıflama sabitini gösterir birimi $1 / \mathrm{m}, \beta$ ise faz kayma sabitini gösterir birimi ise radyan/metre'dir (Akkaş, M.A. 2016). $\alpha$ ve $\beta$ katsayılarının açılımı Eş. 6'da gösterilmiştir.

$$
\begin{aligned}
& \alpha=2 \pi f \sqrt{\frac{\mu \epsilon^{\prime}}{2}\left[1+\left(\frac{\epsilon^{\prime \prime}}{\epsilon^{\prime}}\right)^{2}-1\right]} \\
& \beta=2 \pi f \sqrt{\frac{\mu \epsilon^{\prime}}{2}\left[1+\left(\frac{\epsilon^{\prime \prime}}{\epsilon^{\prime}}\right)^{2}+1\right]}
\end{aligned}
$$

Eş. 6'da gösterilen $\varepsilon$ ' derinin bağıl dielektrik sabitinin gerçek, $\varepsilon$ " ise derinin bağıl dielektrik sabitinin hayali parçalarıdır. $\mu$ ise manyetik geçirgenliği sembolize eder. Bu çalışmada $\varepsilon$ 've $\varepsilon^{\prime \prime}$ değerleri (Gandhi, Om P. ve Abbas R. 1986)'e göre tablo 1'den alınmıştır.

Tablo 1. Derinin Frekanslara göre $\varepsilon^{\prime}$ ve $\varepsilon^{\prime \prime}$ değerleri

\begin{tabular}{|l|l|l|}
\hline Frekans $(\mathbf{G H z})$ & $\boldsymbol{\varepsilon}^{\prime}$ & $\boldsymbol{\varepsilon}^{\prime \prime}$ \\
\hline $\mathbf{3 0}$ & 18.12 & 19.20 \\
\hline $\mathbf{6 0}$ & 8.89 & 13.15 \\
\hline $\mathbf{1 0 0}$ & 5.92 & 8.57 \\
\hline $\mathbf{2 0 0}$ & 4.49 & 4.45 \\
\hline $\mathbf{3 0 0}$ & 4.22 & 2.99 \\
\hline
\end{tabular}

Eş. 7 ortam kaybı ve gürültü de eklenerek aşağıda gösterilmiştir:

$$
\begin{aligned}
P_{r}(d B m) & =P_{t}(d B m)+G_{r}(d B)+G_{t}(d B) \\
- & L_{0}(d B)-L_{\text {Gürültü }}(d B m)-L_{\text {Ortam }}(d B)
\end{aligned}
$$

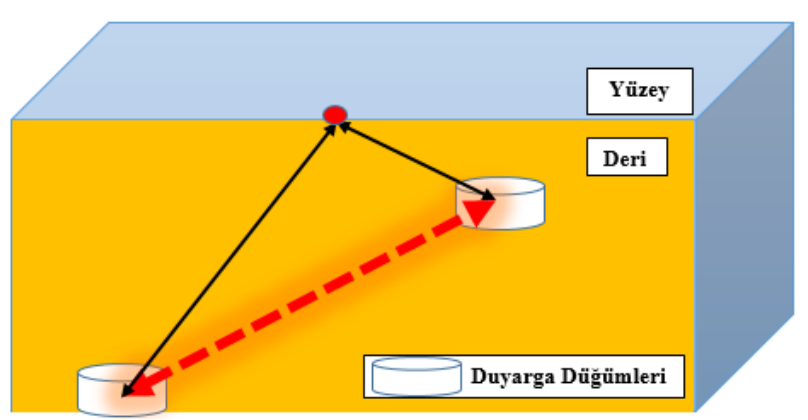

Şekil 3. Deri ortamının tek kanallı modelli 
Şekil 3'te deri ortamının EM dalga iletiminin tek kanallı gösterimi verilmektedir. Kalın kesik çizgi ile gösterilen sinyal, deri ortamında EM dalganın kat ettiği mesafeyi göstermektedir. Analizlerde tek kanallı model incelenmiştir çünkü deri ince bir tabakadır ve boyuna doğru çok sayıda duyarga düğümü koymak anlamsızdır. Uygulamalarda genellikle duyarga dügümü derinin altına yerleştirildiği için Şekil 5 ve Şekil 6 da mesafeye göre analiz sonuçları verilmektedir.

Sistemin BHO'sunu hesaplamak için İkili Faz Kaydırmalı Anahtarlama modülasyon türü seçilip, Eş. 8'de ki gibi sisteme uygulanmıştır. İkili Faz Kaydırmalı Anahtarlamanın seçilmesini amacı ise modülasyon türleri içerisinde ortamdan en az etkilenen ve en uzak mesafeye veri gönderebilen modülasyon türü olmasıdır.

$$
\mathrm{BHO}=0.5 \operatorname{erfc}(\sqrt{\mathrm{SGO}})
$$

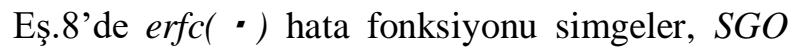
ise sinyal gürültü oranını gösterir.

$$
\mathrm{SGO}=\mathrm{P}_{\mathrm{t}}-\mathrm{P}_{\mathrm{r}}-\mathrm{P}_{\mathrm{n}}
$$

Eş. 9'da $P_{t}$ iletim gücü, $P_{r}$ toplam yol kayb1 gösterir, $P_{n}$ ise gürültünün enerjisini sembolize eder. Yapılan hesaplarda, $P_{t}$ iletim gücü -10 ila $+10 \mathrm{dBm}$ arasında değiştirilmiştir. $P_{n}$ ise eş. 3'e göre hesaplanmıştır (Akkaş, M.A. 2016). $P_{r}$ eş. 7'den elde edilmiştir. $P_{n}$ ise eş. 3'e göre hesaplanmış grafiksel sonuçları ise Şekil 4 'te verilmektedir.

\section{Bulgular}

Şekil 5'te, 2. bölümde anlatılan matematiksel modele göre elde edilen grafik sonuçları yer almaktadır. Şekil 5, $30 \mathrm{GHz}-300 \mathrm{GHz}$ arası frekansta mesafeye göre deri ortamın yol kaybını vermektedir.

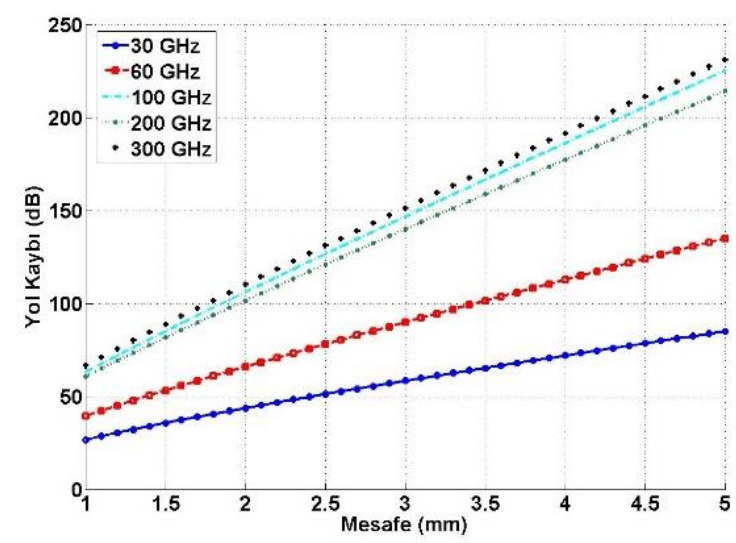

Şekil 5 Deri ortamında mesafeye göre yol kaybı
Şekil 5, eş.7'den elde edilmiştir. Şekil 5 detaylı incelendiğinde, genel olarak frekans arttıkça yol kaybının da arttığ görülmektedir. $100 \mathrm{GHz}-300$ $\mathrm{GHz}(0.1 \mathrm{THz}-0.3 \mathrm{THz})$ aralığında yol kaybı birbirine çok yakın çıkmaktadır. Bunun en büyük sebeplerinden biri $\mathrm{THz}$ ortamında farklılık arz eden eş. 6'da kullanılan Tablo 1'deki $\varepsilon$ ' ve $\varepsilon$ " değerleridir. $\mathrm{THz}$ ortamında $\varepsilon$ ' ve $\varepsilon^{\prime \prime}$ değerleri orantısal olarak değişmez. $\mathrm{THz}$ ortamında tıpkı farklı ortamlarda olduğu gibi deri ortamında da emilim sabiti orantısal olarak değil frekansa göre değişmektedir (Akkaş, M.A. 2016). Normal bir derinin erkeklerde $1.3 \mathrm{~mm}$ olduğu, bayanlarda ise $1.26 \mathrm{~mm}$ olduğu düşünülürse deri ortamında 60 GHz'e kadar 50 dB'nin altında bir kayıp söz konusudur (Wilkinson, P., Millington F. ve R. Skin, 2009). Kullanılan frekans azaltılarak yol kayb1 azaltılabilir fakat bu sefer de anten boyutunun artması söz konusu olacaktır. Takdir edildiği gibi deri altına yerleştirilecek bir telsiz duyarga ağının küçük boyutlarda ve dolayısıyla küçük antenli olması istenir. $100 \mathrm{GHz}-300 \mathrm{GHz}$ $(0.1 \mathrm{THz}-0.3 \mathrm{THz})$ aralığına çıkıldı ̆̆ında ise kayip neredeyse $1.3 \quad \mathrm{~mm}$ 'de $70 \quad \mathrm{~dB}$ 'lere yaklaşmaktadır ki bu kaybın aşılması için oldukça yüksek iletim gücüne ihtiyaç vardır. $\mathrm{THz}$ ortamında yol kaybının artması nano düğümlerin kullanılmasını gerektirmektedir (Akyildiz, I.F. ve Josep M.J. 2010).
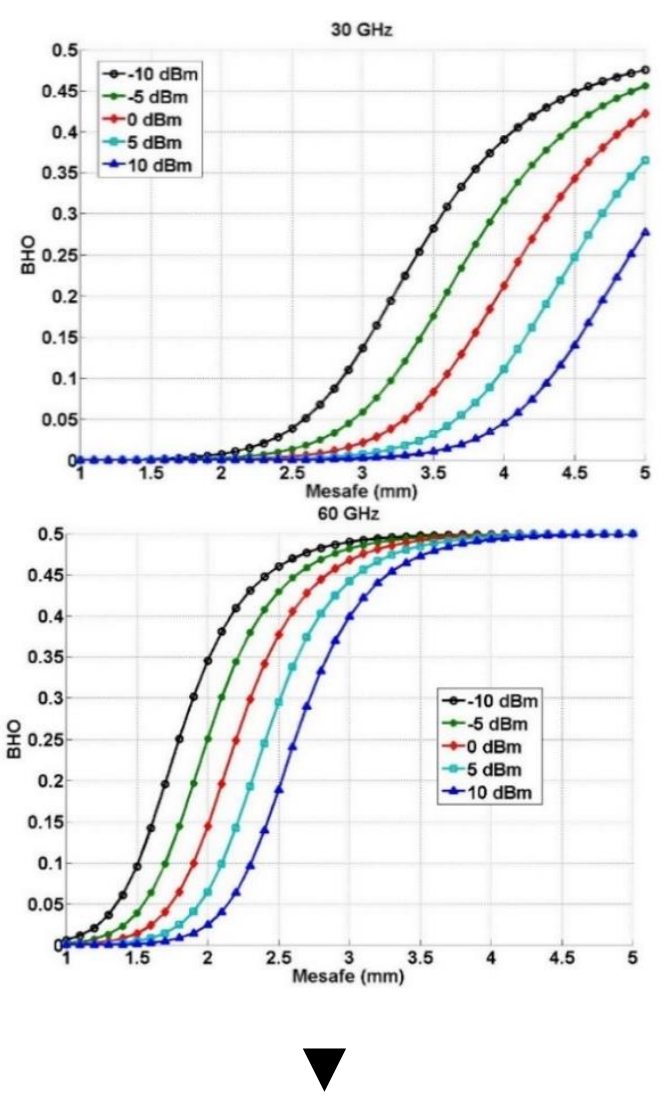


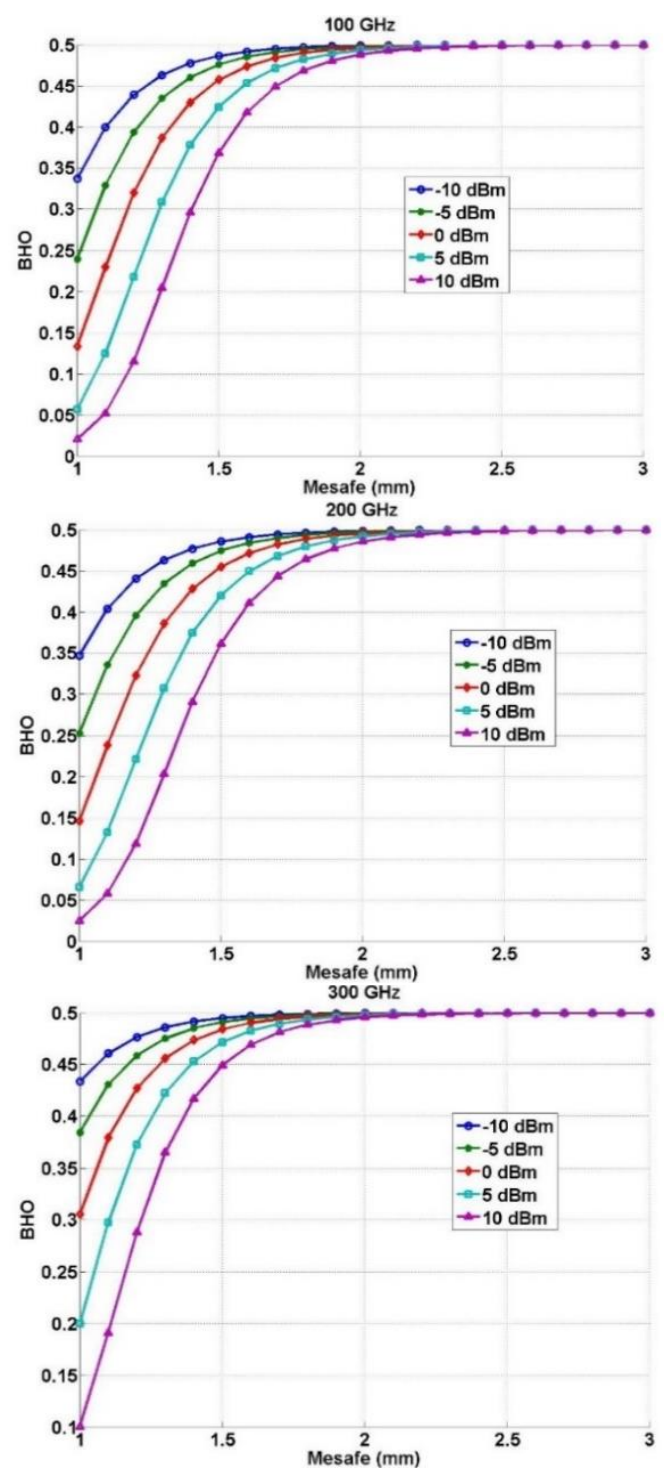

Şekil 6. $30 \mathrm{GHz}-300 \mathrm{GHz}$ deri ortamında mesafeye göre -10 ila $+10 \mathrm{dBm}$ iletim gücü arası BHO'1

Şekil 6'da ise Şekil 5'teki büyüklükler de kullanılarak deri ortamında, mesafeye göre -10 ila $+10 \mathrm{dBm}$ iletim gücü arası BHO'lar, Eş. 8'den elde edilerek verilmiştir. Şekil 6 detaylı incelendiğinde, frekans arttıkça daha kısa mesafelerde daha çok BHO değerine ulaşıldığ görülmektedir. Örneğin Şekil 6a'da neredeyse 2 mm'ye kadar BHO sifir iken bu değer 300 GHz'da 0,5'e kadar yükselmektedir. Şekil 6 da, 10 ila $+10 \mathrm{dBm}$ iletim gücüne göre değişen $\mathrm{BHO}$ verilmiştir. -10 ila $+10 \mathrm{dBm}$ iletim gücü nano ya da mikro boyutta düğümü çalıştırabilecek aralıktır. -10 ila $+10 \mathrm{dBm}$ iletim gücü dikkate alındığında, beklenildiği gibi iletim gücü arttıkça BHO azalmaktadır. $20 \mathrm{dBm}$ 'lik bir fark 30 GHz'da $1 \mathrm{~mm}$ 'den fazla bir iletişim mesafesi sağlarken bu aralık frekans arttıkça azalmaktadır. $300 \mathrm{GHz}$ 'da ise $1 \mathrm{~mm}$ 'de $\mathrm{BHO}-10 \mathrm{dBm}$ 'de 0.45 civarındayken, $10 \mathrm{dBm}$ 'de 0,1 'den başlamaktadır. $\mathrm{Bu}$ sonuç, 1mm'nin bile önemli olduğu $\mathrm{THz}$ ortamında, iletim gücünün çok önemli olduğunu göstermektedir. Sonuç olarak tasarlanmak istenen duyarga düğümleri için Şekil 5 ve Şekil 6 genel olarak bir kılavuz niteliğindedir. $30 \mathrm{GHz}-300$ $\mathrm{GHz}$ arasında oldukça geniş bir frekans aralığında mesafeye göre yol kaybı ve BHO'ları verilmiştir. BHO'lar sadece mesafeye göre değil aynı zamanda iletim gücüne göre de gösterilmiştir.

\section{Tartışma ve Sonuç}

Moleküler haberleşme ve elektromanyetik haberleşme, biyomedikalde kullanılan haberleşme metotlarıdır. Her iki haberleşme metodu vücut içi haberleşmede çok önemlidir. $\mathrm{Bu}$ haberleşme metodu, nesnelerin interneti teknolojisini de kullanarak alışagelmiş sağlık sektöründe çok farklı yenilikler getirecektir. KVAA içinde toplanan verilerin, bir ara yüz vasitası ile ilgili birime iletilmesi gerekmektedir. $\mathrm{Bu}$ ara yüzün görevini deri altı düğümler gerçekleştirecektir. Bu çalışmada insan derisinin elektromanyetik haberleşmeyi ne derece etkilediği, $30 \mathrm{GHz}-300$ $\mathrm{GHz}$ gibi oldukça yüksek bir frekans aralığında ele alınmıştır. Yüksek frekanslarda analiz edilmesinin en önemli sebeplerinden biri, küçük boyutta antenlerin tasarlanmasina yardımcı olmak ve KVAA'da kullanılan nano düğümlerin tasarlanmasında uygun pencere geçişlerini ve kayıpları göstermektedir. Sonuç olarak; kullanılan matematiksel model ve elde edilen grafiksel sonuçlar, şimdiki ve gelecekte tasarlanacak olan deri altı telsiz duyarga ağlarının elektromanyetik haberleşmede derinin etkisini gösteren önemli bir kaynaktır. Bu çalışma göstermektedir ki EM dalgalar deri altından gönderildiğinde, düşük frekanslarda emilim azalmaktadır. Fakat bu sefer anten boyutunu büyütmek gerekmektedir. Frekans değeri arttıkça ise anten boyutu küçülür fakat bu sefer emilim artar. $\mathrm{Bu}$ yüzden tasarımcilar kullanacak oldukları ara yüze göre en ideal frekans aralığını seçmek zorundadır. Bu çalışmada $30 \mathrm{GHz}-300 \mathrm{GHz}$ gibi oldukça geniş frekans aralığında deri ortamının elektromanyetik dalga emilimi, tasarımcılar için matematiksel olarak hesaplanıp grafiksel olarak da gösterilmiştir.

\section{Kaynaklar}

Akkaş, M.A. 2016. Terahertz Channel Modelling of Wireless Ultra-Compact Sensor Networks Using Electromagnetic Waves." IET Communications

Akyildiz, Ian F. ve Josep M. J. 2010. Electromagnetic wireless nanosensor networks." Nano Communication Networks, Cilt 1.1, 3-19. 
Akyildiz, Ian F., vd., 2012 "Monaco: fundamentals of molecular nano-communication networks." IEEE Wireless Communications, Cilt 19.5, 1218

Atakan, B. ve Akan. O.B., 2007 An information theoretical approach for molecular communication." BioInspired Models of Network, Information and Computing Systems, 2007. Bionetics 2007. 2nd. IEEE.

Atakan, B., Akan, O. B., ve Sasitharan B., 2012. Body area nanonetworks with molecular communications in nanomedicine. IEEE Communications Magazine, Cilt 50.1, 28-34

Çoşkun, A., 2011 Hücrelerarası İletişim ve Haberleşme", Bilim ve Teknik, Eylül.

Dixon, Richard A. ve Christopher J. L.., 1990, Molecular communication in interactions between plants and microbial pathogens." Annual review of plant biology, Cilt 41.1, 339367

Gandhi, Om P. ve Abbas R. 1986. Absorption of millimeter waves by human beings and its biological implications." IEEE Transactions on Microwave Theory and Techniques, Cilt 34.2, 228-235
Giné, L. ve Akyildiz I., 2009. Molecular communication options for long range nanonetworks." Computer Networks, Cilt 53.16, 2753-2766.

Ghodgaonkar, D. K., Vasundara V. ve Vijay K., 1989. A free-space method for measurement of dielectric constants and loss tangents at microwave frequencies. IEEE Transactions on Instrumentation and measurement, Cilt 38.3, 789-793.

Nakano, T., vd. 2012. Molecular communication ve networking: Opportunities and challenges IEEE transactions on nanobioscience 11.2 135-148

Pierobon, M. ve Akyildiz, I.F., 2010. A physical endto-end model for molecular communication in nanonetworks. IEEE Journal on Selected Areas in Communications, Cilt 28.4, 602-611.

Roh, W. 2014. Millimeter-wave beamforming as an enabling technology for $5 \mathrm{G}$ cellular communications: theoretical feasibility and prototype results." IEEE Communications Magazine, Cilt 52.2, 106-113

Wilkinson, P., Millington F. ve R. Skin, 2009. Cambridge: Cambridge University Press. pp. 49-50.ISBN 978-0-521-10681-8. 